\title{
UMA ANÁLISE DA PROPOSTA DE TRABALHO COM O GÊNERO DO DISCURSO NOTIICIA EM PLANO DE AULA DE LÍNGUA PORTUGUESA DO PORTAL DO PROFESSSOR ${ }^{1}$
}

\author{
CRISTIANA ABRANTES SARMENTO (UERN) ${ }^{2}$ \\ JOSÉ CEZINALDO ROCHA BESSA (UERN) ${ }^{3}$
}

\begin{abstract}
RESUMO: Este artigo tem como objetivo analisar o trabalho com o gênero do discurso notícia em plano de aula de língua portuguesa do Portal do Professor. O foco recai sobre o exame dos aspectos temáticos, estilísticos e composicionais do gênero do discurso notícia explorado em um plano recortado como corpus do estudo. Interessa responder à seguinte questão: propõe-se efetivamente um trabalho com gênero do discurso e que considere suas especificidades? Como ancoragem teórica, o trabalho assume, principalmente, estudos do Círculo de Bakhtin (BAKHTIN; 2016; MEDVIÉDEV, 2016; VOLÓCHINOV, 2017) sobre a abordagem dialógica e ideológica da linguagem, com ênfase nas discussões sobre gêneros do discurso, e trabalhos de estudiosos que discutem questões ligadas ao ensino de língua materna, dentre os quais Barbosa (2000), Rodrigues (2001), Maieski (2005) e Acosta (2008). As análises realizadas apontam que não há, no plano de aula analisado, uma adequada exploração do conteúdo temático, do estilo e da estrutura composicional enquanto elementos constituintes do gênero, uma vez que a proposta de abordagem desses elementos tanto fica restrita a uma exploração superficial e de maneira genérica do enunciado, quanto se dá a partir de partes fragmentadas deste, desconsiderando, portanto, a concretude do enunciado notícia e suas especificidades.
\end{abstract}

PALAVRAS-CHAVE: Língua portuguesa. Gêneros do discurso. Portal do professor.

ABSTRACT: This article aims to analyze the work with the news discourse genre in Portuguese language lesson plan from the teacher's gate (Portal do Professor). The focus is on examining the thematic, stylistic and compositional aspects of the discourse genre named news, explored in a plan which was selected as the corpus of the study. It is interesting to answer the following question: is it really proposed to work with gender of discourse as well as considering its specificities? As a theoretical perspective, the study adopts, mainly, studies by Bakhtin Circle (BAKHTIN; 2016; MEDVIÉDEV, 2016; VOLÓCHINOV, 2017) on the dialogical and ideological approach of language, with emphasis on discussions about discourse genres, and works by scholars discussing issues related to mother tongue teaching, including Barbosa (2000), Rodrigues (2001), Maieski (2005) and Acosta (2008). The analyzes show that there is not adequate exploration of the thematic content, style and compositional structure in the analyzed lesson plan, as constituent of explored genre, since the proposal of approaching these aspects is restricted to a superficial exploration and in a general way of the utterance, as it happens from fragmented parts of it, disregarding, therefore, the concreteness of the utterance news and its specificities.

KEYWORDS: Portuguese language. Genres of speech. Teacher's gate.

\footnotetext{
${ }^{1}$ O presente trabalho constitui um recorte, com reformulações e ampliações, da dissertação de mestrado intitulada $O$ tratamento dado aos gêneros discursivos em análise linguística: um estudo de planos de aula do Portal do Professor, desenvolvida no âmbito do Programa de Pós-Graduação em Ensino da Universidade do Estado do Rio Grande do Norte/Campus de Pau dos Ferros.

${ }^{2}$ Mestre em Ensino pelo Programa de Pós-Graduação em Ensino da Universidade do Estado do Rio Grande do Norte/Campus de Pau dos Ferros, e-mail: cris_fechosa@hotmail.com

${ }^{3}$ Doutor em Linguística e Língua Portuguesa pelo Programa de Pós-Graduação em Linguística e Língua Portuguesa da Universidade Estadual Paulista Júlio de Mesquita Filho/Campus de Araraquara. Docente do Programa de Pós-Graduação em Ensino e do Programa de Pós-Graduação em Letras da Universidade do Estado do Rio Grande do Norte/Campus de Pau dos Ferros, e-mail: cezinaldobessauern@gmail.com.
} 


\section{$=$ TRAMA $=$}

\section{INTRODUÇÃO}

Assumindo a compreensão bakhtiniana de que toda e qualquer manifestação discursiva se dá por meio de enunciados concretos, únicos e singulares, entendemos ser de suma relevância para a formação de sujeitos competentes, críticos e conscientes do seu papel na sociedade conhecer e compreender os gêneros discursivos em sua diversidade (BRASIL, 1998; BARBOSA, 2000; ANTUNES, 2003). Em consonância com esse modo de pensar, partimos da compreensão de que a adoção dos gêneros discursivos em sala de aula de língua portuguesa permite, como aponta Barbosa (2000), que os professores tenham maior clareza sobre o que precisa ser ensinado e, por consequência disso, os alunos tenham uma visão mais precisa acerca de como produzir e compreender textos em sala de aula.

O pressuposto que orienta esse nosso modo de pensar é que, em vez de se deter em propostas genéricas de discussão que pouco se reportam à situação enunciativa, pode-se explorar as peculiaridades dos gêneros, a partir do seu contexto de produção, circulação e recepção. Esse entendimento representa, pois, tomar como ponto de partida propostas que concebem os textos sem restringi-los a seus aspectos normativos ou a receitas prontas que consistem em tratar os gêneros de uma mesma forma, independentemente da situação enunciativa e dos sujeitos envolvidos (BARBOSA, 2000; GERALDI, 2016, 2017).

Levando em conta a importância e defesa de se trabalhar com gêneros discursivos em sala de aula de língua materna (ANTUNES, 2003, BARBOSA, 2000; SILVA, 2014, dentre tantos outros estudiosos) e sabendo que os professores recorrem não apenas ao livro didático como único recurso para desenvolver propostas de trabalho com gêneros em sala de aula, como também a recursos disponíveis na internet, a saber, sites da Revista Nova Escola e do Portal do Professor, propomo-nos a analisar como são concebidas as propostas de trabalho com gêneros discursivos em planos de aula disponíveis no Portal do Professor. Nosso foco recai sobre o exame dos aspectos temáticos, estilísticos e composicionais do gênero do discurso notícia explorado no plano recortado como corpus deste trabalho. Interessa-nos responder à seguinte questão: propõe-se um trabalho com gênero do discurso que seja efetivo e que considere suas especificidades?

A inquietação que move esta investigação se mostra relevante porque, nesse contexto de defesa cada vez mais crescente das tecnologias digitais e redes sociais na educação (MORAN, 1997; BELEN, 2014; RIBEIRO, 2016; KERSCH, MARQUES, 2017; AZZARI, 2019; dentre outros), é fundamental que o professor não se limite a "reproduzir informações" (DEMO, 2009, 2015) e conteúdos, em circulação no universo digital, que não agregam à formação do aluno e à construção do conhecimento humano. Nesse sentido, o presente trabalho, que se coaduna com estudos de Bessa e Bernardino (2016) e Alves e Bessa (2018), permite examinar conteúdos sobre a abordagem de textos que circulam no universo digital em um contexto específico voltado para a educação, relevando-se, portanto, uma oportunidade de avaliar a pertinência e a adequação desses conteúdos (no nosso caso, dos planos de aula) em relação às concepções que lhe dão ancoragem.

Para fundamentar o nosso trabalho, respaldamo-nos, principalmente, em estudos do Círculo de Bakhtin (BAKHTIN; 2016; MEDVIÉDEV, 2016; VOLÓCHINOV, 2017) sobre a abordagem dialógica e ideológica da linguagem, com ênfase nas discussões sobre gêneros do discurso. Estabelecemos diálogos também com os trabalhos de Barbosa (2000), Rodrigues (2001), Maieski (2005) e Acosta (2008), estudiosos que assumem o pensamento bakhtiniano para discutir questões ligadas, dentre outras, ao ensino de língua materna.

O trabalho inicia com a presente seção de introdução, na qual apresentamos nossa problemática, objetivos e motivação do estudo. Na sequência, trazemos a seção de 


\section{$=$ TRAMA $=$}

fundamentação teórica, em que discutimos acerca dos gêneros do discurso em perspectiva bakhtiniana. Em seguida, temos a seção de metodologia, na qual apresentamos os principais procedimentos metodológicos adotados na realização da pesquisa. Posteriormente, consta a seção de análise do corpus. Nela, concentramos nosso olhar para o exame da proposta de trabalho com o gênero discurso notícia em plano de aula do Portal do Professor. Por fim, temos as conclusões do trabalho realizado.

\section{OS GÊNEROS DISCURSIVOS NA PERSPECTIVA DO CÍRCULO DE BAKHTIN}

De acordo com Bakhtin (2016), todas as nossas atividades estão ligadas ao uso efetivo da linguagem concretizado na forma de enunciados, os quais revelam uma heterogeneidade e diversidade, já que "cada esfera da atividade humana tem sua própria forma de produção, de circulação e recepção de discursos" (SOBRAL, 2009, p. 121). Como cada esfera da atividade humana possui suas peculiaridades enquanto atividade, o uso da língua/linguagem se realizará mediante gêneros discursivos próprios a cada uma das esferas.

Entendendo a língua/linguagem como fenômeno social, a compreensão de gêneros do discurso na perspectiva do Círculo de Bakhtin pressupõe que estes não estão atrelados a frases ou a amontoados de palavras, sem sujeito, sem contexto, mas que eles estão indissoluvelmente ligados às atividades humanas que os sujeitos realizam em contextos historicamente situados. Decorre daí que somente a materialidade linguística dos gêneros dissociada de sua dimensão social/extraverbal não viabiliza a compreensão das diferentes formas de fazer uso da linguagem (VOLÓCHINOV, 2017). Desse ponto de vista, não pode haver uma unidade de comunicação discursiva descolada de suas condições concretas de realização e dos diálogos que se estabelecem entre esferas, conforme Mendonça (2019).

Levando em conta os gêneros discursivos enquanto materialização de enunciados concretos, singulares e únicos na comunicação discursiva, Bakhtin (2016) propõe que cada gênero se caracteriza por meio de três elementos, a saber: conteúdo temático, estilo e estrutura composicional. Nessa perspectiva, o conteúdo temático, o estilo e a estrutura composicional são partes constituintes dos gêneros.

Conforme Rodrigues (2001) e Acosta (2008), o conteúdo temático do gênero está ligado ao seu objeto de discurso e a dados sentidos que são construídos por meio de relações estabelecidas com outros enunciados que se concretizam nesse enunciado. Nesses termos, o tema se constitui a partir das relações dialógicas estabelecidas com outros enunciados no interior de uma dada esfera. O estilo, por sua vez, corresponde aos recursos lexicais e gramaticais da língua (RODRIGUES, 2001) que os sujeitos selecionam, tendo em vista um gênero específico, uma dada intenção comunicativa, assim como um dado interlocutor, com quem está sempre dialogando. Assim sendo, os recursos estilísticos dão conta das escolhas que os sujeitos fazem em situações específicas de enunciação, já que "todo estilo está indissoluvelmente ligado ao enunciado e às formas típicas de enunciados". (BAKHTIN, 2011, p. 17). Já a estrutura composicional corresponde à forma de composição, organização e acabamento do gênero, a qual também leva em conta os sujeitos envolvidos na situação enunciativa, a saber, autor, interlocutor (RODRIGUES, 2001), assim como as finalidades e peculiaridades da esfera em que dado gênero é produzido.

De acordo com Bakhtin (2016), essas características é que determinam a forma dos gêneros se constituírem como "relativamente estáveis", o que significa dizer que eles podem se transformar no uso concreto. Conforme Faraco (2009), o motivo que leva Bakhtin a dizer que os gêneros são relativamente estáveis está atrelado ao fato de termos "de um lado a historicidade dos gêneros; e, de outro, a necessária imprecisão de suas características e fronteiras" (p. 127). Ainda conforme esse autor, os gêneros são históricos e neles se refletem 


\section{$=$ TRAMA $=$}

as mudanças de uma sociedade que é formada por sujeitos que mudam de opinião, adquirem novos conhecimentos, transformam os campos da atividade humana e, por conseguinte, os gêneros - que existem para possibilitar a comunicação entre os falantes de uma sociedade, a qual não é estática e nem imutável, mas dinâmica, pois evolui com o passar do tempo.

Na perspectiva do pensamento do Círculo de Bakhtin, Medviédev (2016) também tece importantes reflexões sobre os gêneros do discurso que colocam em realce a relação entre a língua/linguagem e o universo social, quando aponta que os gêneros se caracterizam a partir de uma dupla orientação na realidade:

[...] em primeiro lugar, a obra se orienta para os ouvintes e os receptores e para determinadas condições de realização e de recepção. Em segundo lugar, a obra está orientada na vida, como se diz, de dentro, por meio do seu conteúdo temático. A seu modo, cada gênero está tematicamente orientado para a vida, para seus acontecimentos, problemas, e assim por diante (MEDVIÉDEV, 2016, p. 195).

Pensando os gêneros do discurso a partir da sua orientação para a realidade, o autor se preocupa com o exterior que constitui os enunciados, apontando claramente a relação constitutiva entre o dizer e a vida dos sujeitos. Com isso, o autor liga os gêneros às ações do sujeito, considerando que essas se diferenciam, a depender dos interesses e do contexto de interação em que estejam envolvidos.

Ainda segundo Medviédev (2016, p. 195), "uma obra entra na vida e está em contato com os diferentes aspectos da realidade circundante mediante o processo de sua realização efetiva, como executada, ouvida, lida em determinado tempo, lugar e circunstâncias". Nesse sentido, o autor aponta que os gêneros do discurso penetram na vida a partir das vivências concretas e singulares dos sujeitos, o que pressupõe as condições de realização de todo dizer, um tempo, um lugar, uma finalidade discursiva, uma esfera, um certo tipo de relação entre os sujeitos envolvidos.

Em conformidade com os pressupostos apresentados acima, podemos compreender que os gêneros estão ligados à vida, ao agir humano, e esse agir, de acordo com Faraco (2009, p. 126), "não se dá de forma independente da interação; nem o dizer fora do agir", considerando-se, portanto, que toda ação humana acontece a partir da comunicação entre os sujeitos (a qual se dá por meio de enunciados que se materializam em um determinado gênero), e todo dizer está diretamente ligado à atividade humana e é sempre revestido de valoração social (VOLÓCHINOV, 2017).

\section{GÊNEROS E ENSINO DE LÍNGUA PORTUGUESA}

Tendo em vista que os planos de aula analisados em nossa pesquisa assumem estabelecer diálogo com as orientações dos Parâmetros Curriculares Nacionais de Língua Portuguesa do ensino fundamental e não com a BNCC, nossa discussão, nesta seção, propõe retomar reflexões que relacionam $o$ ensino de língua materna e os gêneros textuais/discursivos ${ }^{4}$ na proposta do referido documento.

Defendendo a construção de práticas de ensino-aprendizagem efetivas em favor do desenvolvimento da competência comunicativa do aluno, os PCNs sinalizam a necessidade de trabalho constante com diferentes práticas de linguagem, quais sejam: "prática de escuta

\footnotetext{
${ }^{4}$ Mesmo reconhecendo a existência de uma pertinente discussão em torno da questão da distinção entre gêneros do discurso e gêneros textuais (ROJO, 2005; CASSETARI, 2012, BEZERRA, 2017, dentre outros), optamos, neste trabalho, por assumir o termo gêneros do discurso, dada a nossa ancoragem central na perspectiva bakhtiniana.
}

Revista Trama | Volume 16 | Número 37 | Ano 2020 | p. 34-46| e-ISSN 1981-4674 


\section{$=$ TRAMA $=$}

de textos orais e leitura de textos escritos e de produção de textos orais e escritos" (BRASIL, 1998, p. 27). Elegem, nesse sentido, o texto como unidade de ensino e o gênero como objeto de ensino (ROJO, 2000; BARBOSA, 2000).

Como ressalta Rojo (2000), ao tomar os gêneros como objeto de ensino, os PCNs objetivam um trabalho que leve em conta, nas diferentes práticas de linguagem, elementos da situação enunciativa, incluindo aí as influências do contexto em que são produzidos os gêneros, o suporte em que são veiculados, considerando as implicações desses elementos na produção, circulação e recepção dos sentidos.

Os PCNs argumentam em favor de práticas de linguagem a partir do uso da língua nas diferentes situações enunciativas, ao invés do estudo dessas práticas separadas e desvinculadas do contexto real que condiciona esse uso. Nessa direção, pensar o gênero a partir da situação enunciativa implica preparar os sujeitos para falar, ouvir e escrever de diferentes maneiras, a depender das necessidades comunicativas do momento.

Isso supõe o desafio de selecionar conteúdos a serem trabalhados em sala de aula. Desse modo, os PCNs propõem que a escolha dos conteúdos deve se dar de acordo com "as necessidades e possibilidades do aluno", de maneira que, por meio de contínuas aproximações, "se aproprie dos instrumentos" que possibilite "ler, escrever, falar e escutar", (BRASIL, 1998, p. 38), isto é, construir conhecimentos necessários às diferentes atividades de comunicação, partindo do que o aluno sabe para o que ainda não sabe.

Levando em consideração as condições e possibilidades de aprendizagem do aluno, assim como o nível de complexidade do objeto, é que os PCNs propõem uma seleção de gêneros (orais e escritos) a partir de uma progressão em espiral, a qual tem como objetivo possibilitar o progresso do aluno, no que se refere à aprendizagem, priorizando a construção de textos não como uma tarefa que se resume à descrição ou narração como regra geral, mas que considere as tipologias a partir do nível de complexidade do gênero. Dessa maneira é que os alunos, como aponta Barbosa, (2000), podem ter acesso, por exemplo, a gêneros da ordem do argumentar desde as séries iniciais, o que pode resultar em maiores conhecimentos para que ele compreenda cada vez mais sobre os gêneros em situações concretas de interlocução.

Barbosa (2000), ao discutir sobre a progressão dos gêneros a partir dos PCNs e em diálogo com a proposta de Dolz e Scheneuwly (1996), que consiste no agrupamento destes, assinala que essa maneira de propor o trabalho com gêneros possibilita considerar o contexto de enunciação, já que é construída, também, a partir do campo do conhecimento em que estes se situam, o que permite que se considere o contexto histórico e social a partir do domínio social de comunicação. Logo, conforme a autora, essa classificação do gênero por área contribui para uma prática de ensino concreta, firmada na construção do conhecimento, possibilitando, então, que o professor estimule a evolução do aluno, partindo das situações enunciativas menos complexas para as mais complexas.

Nessa perspectiva, conforme os PCNs (BRASIL, 2005, p. 20), "interagir pela linguagem significa realizar uma atividade discursiva: dizer alguma coisa a alguém, de uma determinada forma, num determinado contexto histórico e em determinadas circunstâncias de interlocução". Em consonância com o exposto, na visão dos PCNs, não falamos e nem escrevemos aleatoriamente, mas por meio de um dado gênero, mesmo que, em algumas situações, seja de forma inconsciente.

Decorre daí que aprender a língua "não é tão somente aprender palavras e saber combiná-las em expressões complexas, mas apreender pragmaticamente seus significados culturais e, com eles, os modos pelos quais as pessoas entendem e interpretam a realidade e a si mesmas" (BRASIL, 1998, p. 20). Por esse viés, compreender e saber fazer uso da língua 


\section{$=$ TRAMA $=$}

não significa apenas saber usar as palavras de forma ajustada, ou seja, formar frases legíveis; está, portanto, muito além disso, pois se faz necessário que os sujeitos compreendam seus significados na sua concretude, na sua forma real de se manifestar, a partir de dadas situações comunicativas.

De acordo com Barbosa e Nunes (2000), entende-se que os PCNs defendem um ensino de línguas que tem como foco os diferentes gêneros que circulam na sociedade e tornam possível a comunicação entre os sujeitos, não se limitando aos aspectos estruturais da língua que, apesar de fazerem parte dela, não dão conta desta como fenômeno social. Nesse sentido, e conforme assinalam Barbosa e Nunes (2000, p. 94), as propostas apresentadas pelos PCNs visam "oferecer subsídios para um ensino que permita aos alunos o uso eficaz da leitura e da escrita e dos benefícios decorrentes de sua apropriação, como a diminuição do fracasso escolar e a possibilidade efetiva do exercício da cidadania".

Ainda sobre a relevância de se pensar um trabalho em sala de aula construído tomando como embasamento as orientações dos PCNs, Barbosa e Nunes (2000, p. 103) nos lembram:

[...] seguir as orientações dos PCNs, nesse caso, supõe modificar as práticas de linguagem estabelecidas sobre uma concepção abstrata de língua como objeto de estudo, por uma concepção enunciativa, discursiva de língua em que as condições da interlocução necessitam ser consideradas como determinantes para seu estudo.

Assim sendo, adotar as orientações dos PCNs no que compete ao ensino de Língua Portuguesa implica a transformação das práticas de linguagem, no sentido de adotar uma concepção enunciativa de língua em detrimento de uma concepção abstrata. Em consonância com o dito, são contribuições que permitem pensar e realizar um trabalho com a linguagem calcado na interação para além dos limites da frase, percebendo a língua como um fenômeno histórico e social.

\section{METODOLOGIA}

Este artigo é um recorte de uma dissertação de mestrado na área de ensino de línguas que teve como foco o tratamento dado aos gêneros discursivos em planos de aula de língua portuguesa do Portal do Professor. Para tal empreendimento, apoiamo-nos em pressupostos da abordagem dialógica bakhtiniana e em trabalhos de pesquisadores que discutem sobre o ensino de língua materna.

Considerando o foco de nossa investigação e a fundamentação teórico-metodológica adotada, podemos dizer que nosso estudo se caracteriza como uma pesquisa de natureza interpretativa e de abordagem qualitativa, segundo a visão de Engel e Silveira (2009) e Laville e Dionne (1999). Seguindo esses direcionamentos metodológicos próprios de investigações no campo das ciências humanas, entendemos que o exercício do pesquisador consiste em construir sentidos acerca daquilo que o nosso "sujeito falante" expressa.

Em consonância com o exposto, elegemos como corpus de análise 01 plano ${ }^{5}$ de aula de língua portuguesa direcionado ao ensino fundamental II, coletado 6 do Portal do Professor. O referido Portal é um site educacional do Ministério da Educação (MEC) do Brasil que se

\footnotetext{
${ }^{5}$ Embora na dissertação trabalhemos com um corpus mais amplo, optamos aqui pelo exame de 01 único plano por duas razões principais: por entendemos que cada gênero discursivo constitui um evento único e singular, o que implica abordá-lo em suas singularidades e especificidades; e por questões de espaço, já que o acréscimo da análise de um outro plano extrapolaria a extensão permitida para publicação do artigo.

${ }^{6}$ A coleta do corpus da pesquisa aconteceu no dia 15 de novembro de 2017.
} Revista Trama | Volume 16 | Número 37 | Ano 2020 | p. 34-46| e-ISSN 1981-4674 


\section{$=$ TRAMA $=$}

constitui como um espaço de divulgação/propagação de materiais didáticos para diferentes áreas de ensino, especialmente da educação básica, o qual tem como foco o compartilhamento desses materiais com diversos educadores de todo o país.

O site é composto de algumas seções, tais como: Multimídia, Recursos educacionais, Materiais de estudo, Notícias, Colaboração, Links. Além disso, dispõe da opção Visite e do Espaço da aula. Para uma melhor compreensão do funcionamento do site, apresentamos a imagem abaixo que ilustra a página inicial do referido portal.

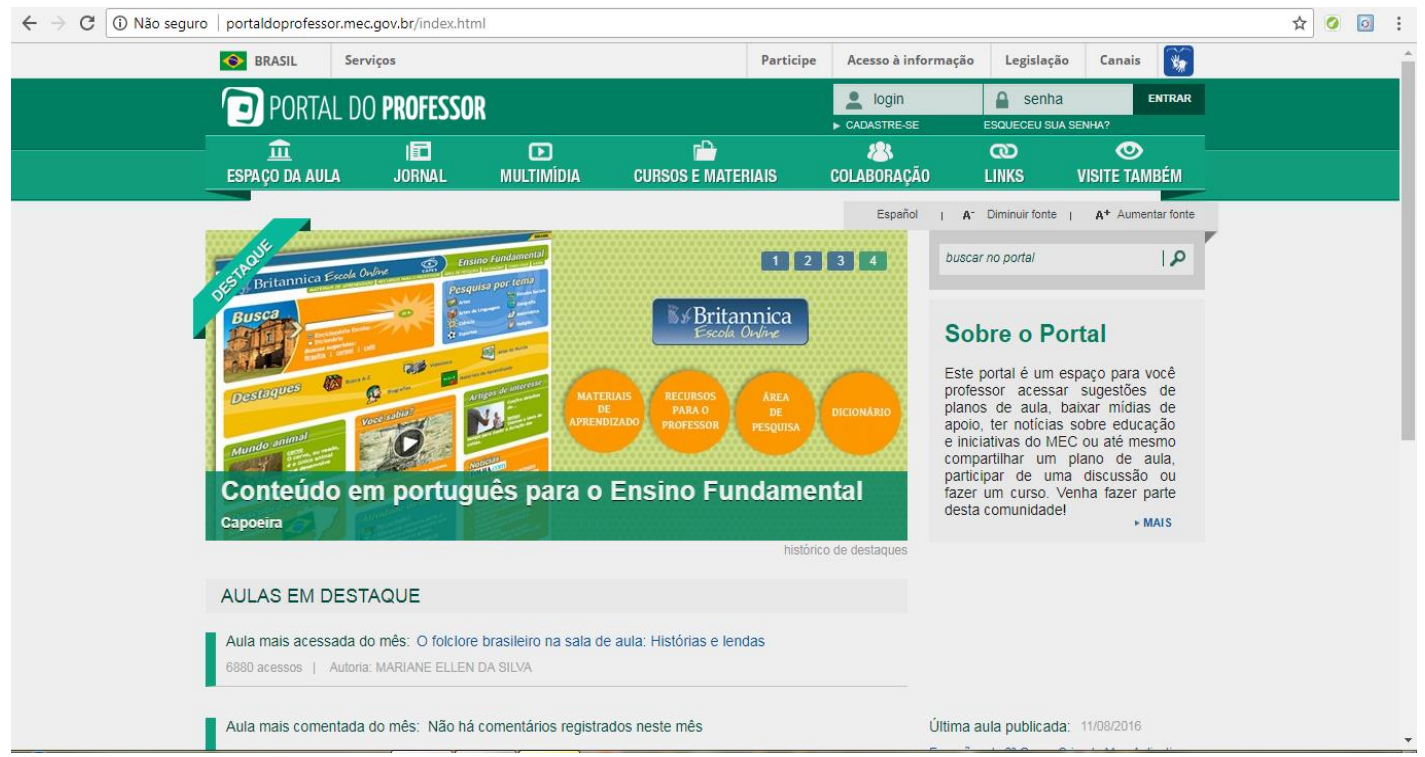

Figura 1: Página principal do Portal do professor

A seção Espaço da Aula, que nos interessa mais diretamente aqui, é onde se encontram os planos de aula que selecionamos para nossa pesquisa. Nessa seção, podemos ter acesso a planos de aula de diferentes disciplinas direcionados a turmas de alunos do Ensino Fundamental e Médio. Nela, o professor pode entrar e conhecer diferentes propostas de atividades, as quais podem ser visualizadas por assunto; nível de ensino, etc. Além disso, é possível também emitir opiniões sobre os planos de aula, assim como criar novos materiais, caso o professor queira.

Para a criação de planos de aula, é preciso que o professor se cadastre no site, faça um login e siga as orientações do passo-a-passo que o portal dispõe para quem deseja construir materiais didáticos e socializar com outros professores. Assim, por meio desse site é possivel acessar, compartilhar, baixar e criar diferentes materiais didáticos.

\section{A PROPOSTA DE TRABALHO COM O GÊNERO DO DISCURSO NOTÍCIA EM PLANO DE AULA DE LÍNGUA PORTUGUESA DO PORTAL DO PROFESSOR}

Partindo da compreensão de que propostas de trabalho com o texto na sala de aula de língua portuguesa não podem ignorar a exploração dos elementos que constituem os gêneros discursivos (conteúdo temático, o estilo e a estrutura composicional), nossa atenção aqui se centra no modo como esses elementos são explorados em um plano de aula de língua portuguesa do ensino fundamental recortado do Portal do Professor. Para tanto, utilizaremos exemplos de recortes de atividades de um plano cuja proposta se volta ao trabalho com o 


\section{$=$ TRAMA $=$}

gênero notícia, disponível para acesso no seguinte endereço: http://portaldoprofessor.mec.gov.br/fichaTecnicaAula.html?aula=22646.

Antecipamos que apenas por uma questão didática optamos por explorar, na nossa análise, cada elemento do gênero de modo separado, já que, em conformidade com o pensamento bakhtiniano, a relação forma/conteúdo é indissociável em seu funcionamento concreto, não sendo possível pensar num tratamento de cada elemento de maneira estanque.

É preciso destacarmos, inicialmente, que o plano recortado, intitulado Sobre o gênero discursivo - notícia, parte de 03 objetivos $^{7}$ que são concebidos para possibilitar o reconhecimento e domínio do gênero proposto. Vejamos:

- identificar a notícia como um gênero discursivo da esfera jornalística;

- analisar os elementos da estrutura composicional da notícia impressa: autoria, título, foto, legenda, olho e lead;

- produzir uma notícia, de acordo com a estrutura estudada

Observamos aí que são propostos, no plano, objetivos que deem conta tanto da compreensão sobre o funcionamento e estruturação do gênero, os dois primeiros, como de sua produção, o último deles. Destacamos a ênfase que se dá, no primeiro objetivo, no estudo da notícia como gênero do discurso; e da estrutura composicional, no segundo. Não são explicitados, textualmente, a exploração dos aspectos estilísticos e do conteúdo temático, a menos que façamos o esforço de imaginar que esses dois elementos da constituição dos gêneros estejam contemplados no primeiro objetivo. Parece-nos, entretanto, que a ênfase, muito pertinente desse primeiro objetivo, está em relacionar o gênero a sua esfera de produção, à esfera jornalística, logo, cogitamos que seja pouco provável que esse objetivo comporte também um acento em aspectos estilísticos e de conteúdo temático.

A despeito dessa constatação inicial, já indicativa do que podemos esperar da exploração do gênero notícia no plano, centremos nossa atenção na exploração do conteúdo temático. É preciso adiantar que, no plano, não se concebe a ideia de explorar o conteúdo temático. Há apenas um encaminhamento voltado à exploração do assunto, como podemos observar no excerto a seguir:

O professor deverá levar os alunos ao laboratório de informática para, em dupla, acessarem a página do jornal "Folha de São Paulo", seguindo o roteiro abaixo. Acesse o portal do jornal Folha de São Paulo

Clique em notícias

Leia a notícia selecionada e responda no caderno:

Qual é o assunto da notícia?

$\mathrm{Na}$ intenção de explorar o assunto da notícia, a atividade encaminhada solicita que os alunos, em dupla, acessem a página do jornal Folha de S. Paulo, selecionem e leiam uma notícia e respondam qual o assunto dela. Desse modo, ao centrar a exploração no assunto da notícia, a questão parece ficar no limite do que está posto, viabilizando uma compreensão, quando muito, superficial do que seria o conteúdo temático de uma notícia.

Nessas circunstâncias, a questão parece potencialmente pertinente quando encaminha que aluno acesse a página do jornal Folha de S. Paulo - espaço de produção/circulação de informações e opiniões atuais, de interesse público - o que poderia influenciar o aluno a compreender como este se constitui e funciona enquanto meio de

\footnotetext{
${ }^{7}$ Uma descrição da organização/estruturação do plano recortado para exame pode ser encontrada na seção de metodologia da dissertação de Sarmento (2018), para a qual remetemos o leitor, caso deseje se aprofundar na compreensão do material analisado.
}

Revista Trama | Volume 16 | Número 37 | Ano 2020 | p. 34-46| e-ISSN 1981-4674 


\section{$=$ TRAMA $=$}

divulgação de informações e opiniões. Contudo, tal direcionamento precisaria levar em conta a dimensão extraverbal do gênero, que não é sinalizada. Frente a essa limitação do plano, caberia, pois, o papel de mediação do professor no sentido de estabelecer essa ponte.

Além disso, observamos que, ao objetivar a exploração apenas do assunto da notícia, por meio do seguinte questionamento: "qual é o assunto da notícia?", o plano parece reduzir a abordagem do conteúdo temático à identificação do objeto do discurso, sem se remeter aos sentidos que são construídos com base nesse objeto, isto é, as informações noticiadas. De acordo com Acosta (2008, p. 112), "o horizonte temático do gênero não está único e exclusivamente ligado e perpassado pela noção de assunto", mas vai além e leva em conta as relações dialógicas construídas no diálogo entre escrevente e possíveis leitores, a partir do lugar, bem como da esfera da atividade humana em que os sujeitos estão inseridos.

Desse modo, a questão em análise, ao levar em conta apenas o assunto da notícia deixa de lado os sentidos que poderiam ser construídos a partir das informações noticiadas por um determinado sujeito que, por não ser neutro, deixa marcas de sua maneira de propagar e divulgar fatos, assim como as marcas de um querer dizer que ele não constrói sozinho, mas em diálogo com os já-ditos e com as respostas antecipadas de seus interlocutores. Isso porque o que o jornal Folha de S. Paulo expressa, responde a algo já-dito, bem como busca resposta de seus possíveis interlocutores (BAKHTIN, 2016), tendo em vista que estes participam ativamente da construção de todo e qualquer texto jornalístico.

Com base no exposto, podemos dizer que, ao considerar a exploração de questões como esta, o professor estará possibilitando que um exemplar de um gênero discursivo adentre a sala de aula, oportunizado ao aluno interagir com esse tipo de enunciado. Porém, o encaminhamento dado não nos permite enxergar que se viabiliza a necessária compreensão acerca do que motivou e orientou a construção do enunciado, as relações dialógicas que the são constitutivas, assim como as intenções que conduzem a vontade enunciativa, o querer dizer do autor, aspectos esses que, conforme concebe Bakhtin (2016), uma abordagem da materialidade textual, centrada estritamente no estudo do assunto da notícia, por si só não dá conta.

Quanto ao estilo, convém relembrar, de antemão, que os objetivos não explicitam uma preocupação em torno de uma exploração desse elemento. Ainda assim é possível observarmos, no plano, a presença de alguns aspectos dos usos da linguagem (tempo verbal, pessoa verbal, objetividade e clareza da linguagem) que sinalizam a possibilidade de exploração, mesmo que de maneira muito genérica, do estilo na notícia recortada, conforme verificamos no excerto seguinte:

Em relação à linguagem responda: em que tempo e pessoa foram empregados os verbos? A linguagem é clara e objetiva? Justifique

Um aspecto que chama atenção, incialmente, é a proposta desse plano de abordar tempo do verbo, pessoa do verbo, clareza e objetividade da linguagem em uma só questão, quando se acredita que cada um desses elementos de uso da linguagem poderia ser tomado em questões distintas, para, assim, poder viabilizar uma compreensão mais aprofundada das intenções que cada uma dessas escolhas produz no enunciado, e, de modo mais particular, no exemplar de notícia recortado.

Em relação ao tempo verbal, poder-se-ia, por exemplo, explicitar que, na construção da notícia, a escolha é, comumente, pelo uso do verbo no pretérito do indicativo, já que, nesse gênero, a recorrência a esse elemento serve, conforme Acosta (2008), para marcar a narração de um acontecimento que se deu no passado e está sendo revalorado e, por 


\section{$=$ TRAMA $=$}

conseguinte, reenunciado pelo autor do enunciado. Já quanto à pessoa gramatical, poder-seia apontar que, no gênero notícia, há uma predileção pela $3^{a}$ pessoa do singular ou do plural (ele/ela; eles/elas), cujo uso é sempre intencionado, servindo para marcar um distanciamento do sujeito que escreve a notícia em relação aos fatos relatados, de modo a contribuir, portanto, para confirmar o efeito de objetividade que se espera de um enunciado pertencente ao gênero notícia (BENASSI, 2009).

Chama atenção também, nesse plano, o fato de não haver uma preocupação com a função desses elementos no funcionamento do gênero notícia, dando a entender que o aluno deve apenas identificá-los e/ou localizá-los, sem se remeter aos efeitos de sentido que as escolhas deles imprimem ao projeto de dizer do enunciado, bem como ao que levou o autor da notícia a escolher uma dada pessoa gramatical, um dado tempo verbal e uma determinada forma de linguagem para atender às determinações do veículo de comunicação e de seus possíveis interlocutores.

Assim, compreendemos que, quando se trata de explorar o estilo, não basta que o aluno tão somente encontre e/ou localize um aspecto específico relativo ao uso da linguagem, mas é preciso ir além disso, procurando mostrar para o aluno que a escolha por dada pessoa verbal, por exemplo, se dá pelo fato de não caber nesse gênero elementos que denunciem explicitamente o posicionamento e a subjetividade do escrevente, assim como do espaço de produção de dado enunciado. Ademais, é preciso destacar que uma adequada abordagem do estilo no estudo de gêneros do discurso, tal como pensada por Bakhtin (2016), não pode deixar de considerar os aspectos do estilo do gênero e aqueles que são próprios da individualidade do produtor/autor do enunciado, dado esse que reitera que os aspectos estilísticos são superficialmente contemplados na proposta de trabalho do plano analisado.

A propósito da estrutura composicional, cumpre apontar que se trata do elemento mais explorado no plano, demonstrando, assim, uma coerência com o que é anunciado no segundo objetivo deste. No plano analisado, a proposta é explorar a estrutura composicional do gênero notícia tomando por base dois enunciados desse gênero: o primeiro recortado do portal Folha uol, que relata sobre um acidente com cinco pessoas feridas ocorrido em São Paulo; e, o segundo, recortado do portal G1 globo, que anuncia a realização de um show, no Rio de Janeiro e em São Paulo, do grupo de rock liderado por Bon Jovi. É com base nessas duas notícias que são propostas as questões que seguem:

\footnotetext{
Uma notícia bem estruturada apresenta a seguinte forma:

TÍTULO: a notícia deve ser encabeçada por um título expressivo para chamar a atenção do leitor. O título relaciona-se com o lead e pode apresentar um subtítulo.

LEAD OU PARÁGRAFO GUIA: primeiro parágrafo, em que se resume o fato acontecido. É uma parte fundamental da notícia que além de captar a atenção do leitor, tem como objetivo fornecer-lhe informações fundamentais, respondendo as perguntas: quem? o que? onde? quando?

CORPO DA NOTÍCIA: parágrafo (s) em que se faz a descrição pormenorizada dos fatos ocorridos. Nesta segunda parte, responde-se às questões: como? por quê?

As notícias analisadas estão estruturadas nesse formato?

Transcreva o LEAD de cada uma das notícias - 1 e 2.
}

Podemos observar que, após discorrer sobre as partes que constituem a notícia, o encaminhamento proposto solicita que o aluno verifique, inicialmente, se as notícias analisadas estão de acordo com o modelo de estrutura exposto na questão, e pede, em seguida, que o aluno realize a transcrição do lead das notícias já mencionadas. 


\section{$=$ TRAMA $=$}

Essa proposta de atividade, além de partir de noções gerais acerca de como se estrutura uma notícia - uma vez que não parte dos próprios exemplares indicados, mas de uma descrição de como deve ser, ao invés de se deter ao como se constitui - não leva em conta a construção textual das notícias, mas fica na análise da estrutura sem se ater aos elementos que condicionam essa estrutura, os quais contribuem, de forma significativa, para compreender como os autores das notícias organizaram seu projeto de dizer e as estratégias que eles mobilizam para chamar a atenção de seus leitores.

Desse modo, essa proposta de exploração da estrutura composicional do gênero notícia nos leva a compreender que a visão que se tem sobre a estrutura composicional é que ela é sempre igual para todos os exemplares de notícia, não se considerando aí, portanto, a relativa estabilidade do gênero de que fala Bakhtin (2016). Não se tem em vista, pois, que, dependendo do espaço em que enunciados circulam e das informações noticiadas, as notícias podem apresentar estrutura composicional que se diferencia pelo fato de pertencerem a jornais que, certamente, possuem posicionamentos ideológicos que não são semelhantes. Nesse sentido, podemos questionar: não seria mais pertinente orientar os alunos a analisarem a construção composicional de cada uma das notícias considerando também as suas especificidades e singularidades?

Não menos merecedor de atenção a abordagem da estrutura composicional da notícia é o direcionamento final, solicitando que o aluno realize uma transcrição do lead de cada uma das duas notícias. Se, por um lado, tal exercício pressupõe que o aluno estabeleça contato com cada uma das notícias, por outro, parece se preocupar com a atividade de copiar de um espaço para outro, sem se deter ao querer dizer de cada um dos autores que, ao elaborarem o lead, fazem escolhas estilísticas e se posicionam, haja vista o propósito de chamar atenção e situar o seu leitor acerca do fato que está sendo noticiado.

Levando em conta as questões suscitadas até aqui sobre a proposta de trabalho com o gênero notícia no plano analisado, podemos dizer que há nele uma preocupação maior em fornecer elementos sobre a materialidade linguística dos enunciados que objetivam explorar. Faltam, todavia, mais elementos que visem a instigar o aluno a querer saber sobre como os autores constroem o seu querer dizer e como projetam sentidos acerca do que se propõem a enunciar, contemplando, assim, de forma mais rica e aprofundada, o funcionamento complexo e multifacetado de cada gênero, o que pressupõe focar o conteúdo temático, o estilo e a estrutura composicional de cada gênero do discurso em sua unicidade e eventicidade, consoante concebe Bakhtin (2016).

\section{CONCLUSÃO}

Assumindo que os gêneros do discurso devem ocupar um lugar central - não exclusivo - no ensino de língua portuguesa na educação básica e compreendendo a necessidade de lançar um olhar investigativo sobre propostas de trabalho que se materializam em recursos didáticos como planos de aula disponíveis no universo digital, nosso trabalho teve como objetivo analisar como são concebidas as propostas de trabalho com gêneros discursivos em planos de aula disponíveis no Portal do Professor.

Seguindo os princípios de uma pesquisa interpretativa e de abordagem qualitativa, nosso trabalho contemplou o exame da exploração dos aspectos temáticos, estilísticos e composicionais do gênero discursivo notícia em um plano de aula de língua portuguesa recortado do portal supracitado.

A análise realizada nos possibilitou compreender que não há, no plano de aula analisado, uma adequada exploração do conteúdo temático, do estilo e da estrutura composicional enquanto partes constituintes do gênero explorado, tendo em vista que a Revista Trama | Volume 16 | Número 37 | Ano 2020 | p. 34-46| e-ISSN 1981-4674 


\section{$=$ TRAMA $=$}

abordagem desses aspectos tanto fica restrita a uma exploração superficial e de maneira genérica do enunciado, quanto se dá a partir de partes fragmentadas deste. Fica evidente, pois, uma ênfase mais acentuada no estudo da estrutura composicional, porém, sem contemplar plenamente a compreensão de que os gêneros são fenômenos sócio históricos vinculados às esferas da atividade humana.

Feitas essas ressalvas e considerando os problemas que o plano analisado apresenta no que se refere à exploração dos aspectos temáticos, estilísticos e composicionais do gênero notícia, julgamos que se faz necessário que o professor de língua portuguesa disponha de conhecimentos teóricos consistentes para que possa avaliar até que ponto esses conteúdos relacionados à educação que circulam na internet, e em particular nesses recursos didáticos disponíveis em portais como o Portal do Professor, podem ser pertinentes e adequados para colaborar com a sua prática de sala de aula.

Cremos, portanto, que o professor de língua portuguesa precisa estar muito atento a essa dinâmica de circulação de conteúdos do universo digital e se constituir como um consumidor crítico e autônomo desses conteúdos numa perspectiva de construção do conhecimento e de sua formação enquanto autor de suas aulas (DEMO, 2009; 2015), para que possa contribuir cada vez mais com a formação de alunos com vez e voz para atuar criticamente em sociedade por meio da palavra. Assim, o presente estudo nos levou a alargar a nossa compreensão no sentido de que é preciso, antes de tudo, que o professor participe como autor das atividades que se propõe a executar em sala de aula, o que implica a construção e a reconstrução do conhecimento e não apenas a mera reprodução de conteúdos sem autoria (DEMO, 2009; 2015) e, por assim dizer, sem a sua participação ativa.

\section{REFERÊNCIAS}

ACOSTA, P, R. O gênero jornalístico notícia: dialogismo e valoração. Dissertação (Mestrado em Linguística). Programa de Pós-graduação em Linguística. Florianópolis: UFSC, 2008.

ALVES, W. M.; BESSA, J. C. R. Orientações para escrita da redação do Enem em vídeos do Youtube. Hipertextus Revista Digital, v. 19, p. 1-23, 2018.

AZZARI, E. F. EFL collaborative writing: text production and online resources. Diálogo das Letras, Pau dos Ferros, v. 8, n. 1, p. 52-65, jan./abr. 2019.

BAKHTIN, M. Os gêneros do discurso. Organização, tradução, posfácio e notas de Paulo Bezerra. São Paulo: Editora 34, 2016.

BARBOSA. J. P. Do professor suposto pelos PCNs ao professor real de língua portuguesa: são os PCNs praticáveis? In: ROJO. R. (Org). A prática de linguagem em sala de aula: praticando os PCNs. São Paulo: Mercado de Letras, 2000, p. 149-175.

BARBOSA. M. S; NUNES. R. H. Os PCNs: uma experiência de formação de professores do Ensino Fundamental. In: ROJO. R. (Org). A prática de linguagem em sala de aula: praticando os PCNs. São Paulo: Mercado das Letras, 2000, p. 93-126.

BELEN, B. de C. O blog como ferramenta pedagógica no ensino de produção escrita em língua inglesa no PARFOR. Diálogo das Letras, Pau dos Ferros, v. 03, n. 01, p. 87-106, jan./jun. 2014.

BEZERRA, B. G. Gêneros no contexto brasileiro: questões [meta] teóricas e conceituais. São Paulo: Parábola Editorial, 2017.

BENASSI, M. V. B. O gênero notícia: uma proposta de análise e intervenção. In: CELLI - COLÓQUIO DE ESTUDOS LINGUÍSTICOS E LITERÁRIOS. 3, 2007, Maringá. Anais... Maringá, 2009, p. 1791-1799.

Disponível em:ple.uem.br/3celli_anais/trabalhos/estudos_linguísticos/069.pdf. Acesso em: 06 jun. 2018. BESSA, J. C. R.; BERNARDINO, R. A. S. Equívocos em torno da escrita: o caso das dicas de produção de textos em vídeos do YouTube. Domínios de Lingu@Gem, v. 11, p. 174, 2016.

BRASIL. SEF. Parâmetros curriculares nacionais: terceiro e quarto ciclos do ensino fundamental: língua portuguesa. Brasília: MEC/SEF, 1998.

CASSETTARI, M. I. Tipo, gênero textual e gênero do discurso: em busca de uma definição para o ensino.

Diálogo das Letras, Pau dos Ferros, v. 01, n. 02, p. 132 - 151, jul./dez. 2012.

DEMO, P. O educador e a prática da pesquisa. Ribeirão Preto: Editora Alphabeto, 2009.

DEMO, P. Aprender como autor. São Paulo: Atlas, 2015.

DOLZ, J.; SCHNEUWLY, B. Gêneros e progressão em expressão oral e escrita: elementos para reflexões sobre uma experiência suíça (francófona). Tradução de Roxane Rojo. Enjeux, p. 31 -49, 1996.

ENGEL, T. G; SILVEIRA, D.T. Métodos de pesquisa. Porto Alegre: Editora da UFRGS, 2009. 


\section{$=\mathrm{T} R A M A=$}

FARACO, C. A. Linguagem \& diálogo: as ideias Linguísticas do círculo de Bakhtin. Curitiba: Parábola Editorial, 2009.

GERALDI, J. W. Dialogia: do discurso à estrutura sintática. In: RODRIGUES. R. H.; ACOSTA. R. P. (Org). Estudos dialógicos da linguagem e pesquisa em linguística aplicada. São Carlos: Pedro \& João Editores, 2016, p. 179-189.

KERSCH, D. F.; MARQUES, R. G. Redes sociais digitais na escola: possibilidades de conexão, produção de sentido e aprendizagem. Diálogo das Letras, Pau dos Ferros, v. 06, n. 02, p. 343-362, jul./dez. 2017. LAVILLE, C.; DIONNE, J. A construção do saber: manual de metodologia da pesquisa em ciências humanas. Tradução de Heloisa Monteiro e Francisco Settineri. Portalegre: Artes Médicas, Sul Ltda,; Belo Horizonte: Editora UFMG, 1999.

MAIESKI, M. N. O gênero do discurso artigo como objeto de ensino-aprendizagem: uma proposta de integração da prática de produção textual à leitura e à análise linguística. 2005. 209f. Dissertação (Mestrado em Linguística) - Programa de Pós-Graduação em Linguística, Universidade de Santa Catarina, 2005. MEDVIÉDEV. P. N. O método formal nos estudos literários: introdução crítica a uma poética sociológica. Tradição de Ekaterina Vólkova Américo e Sheila Camargo Grillo. São Paulo: contexto, 2016.

MENDONÇA, M. C. A produção textual na esfera escolar: considerações sobre a "escrita como trabalho". Diálogo das Letras, Pau dos Ferros, v. 8, n. 1, p. 3-15, jan./abr. 2019.

MORAN, J. M. Como utilizar a internet na Educação. Ciência da Informação, BRASÍLIA, v. 26, n. 2, p. $146-$ 153, 1997.

RIBEIRO, A. E. Tecnologia digital e ensino: breve histórico e seis elementos para a ação. Linguagem \& Ensino, Pelotas, v.19, n.2, p. 91-111, jul./dez. 2016.

RODRIGUES, R. H. A constituição e funcionamento do gênero jornalístico artigo: cronotopo e Dialogismo. 2001. 347f. Tese (Doutorado em Linguística Aplicada e Estudos da Linguagem). Pontifícia Universidade Católica de São Paulo, São Paulo, 2001.

ROJO, R. Gêneros do discurso e gêneros textuais: questões teóricas e aplicadas. In: MEURER, J. L.; BONINI, A.; MOTTA-ROTH, D. (Org.). Gêneros: teorias, métodos, debates. São Paulo: Parábola, 2005, p.184-207. SILVA, S. L. Algumas considerações sobre memorial de leitura e a constituição do ethos discursivo na formação inicial do professor de língua portuguesa. Diálogo das Letras, Pau dos Ferros, v. 03, n. 02, p. 05-22, jul./dez. 2014.

SARMENTO, C. A. O tratamento dado aos gêneros discursivos em análise linguística: um estudo de planos de aula do Portal do Professor. 2018. 121 f. Dissertação (Mestrado em Ensino) - Programa de Pós-Graduação em Ensino. Universidade do Estado do Rio Grande do Norte, Pau dos Ferros, 2018.

SOBRAL, A. Do dialogismo ao gênero: as bases do pensamento do círculo de Bakhtin. Campinas: Mercado de Letras, 2009.

SUASSUNA, L.; BERNARDINO, R. A. S. Passando em revista ideias sobre o ensino de língua portuguesa: uma entrevista com João Wanderley Geraldi. Diálogo das Letras, Pau dos Ferros, v. 06, n. 01, p. 490-496, jan./jun. 2017.

VOLÓCHINOV, V. Marxismo e filosofia da linguagem: problemas fundamentais do método sociológico na ciência da linguagem. Tradução de Sheila Grillo e Ekaterina Vólkova. São Paulo: Editora 34, 2017. 